\title{
Communication failures in patient sign-out and suggestions for improvement: a critical incident analysis
}

\author{
V Arora, J Johnson, D Lovinger, H J Humphrey, D O Meltzer
}

Qual Saf Health Care 2005;14:401-407. doi: 10.1136/qshc.2005.015107

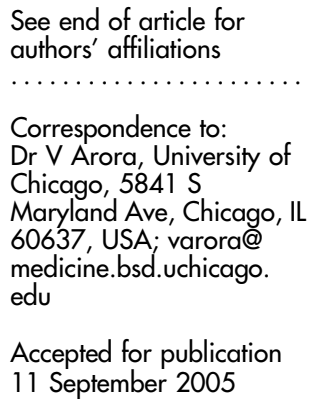

\begin{abstract}
Background: The transfer of care for hospitalized patients between inpatient physicians is routinely mediated through written and verbal communication or "sign-out". This study aims to describe how communication failures during this process can lead to patient harm.

Methods: In interviews employing critical incident technique, first year resident physicians (interns) described (1) any adverse events or near misses due to suboptimal preceding patient sign-out; (2) the worst event due to suboptimal sign-out in which they were involved; and (3) suggestions to improve signout. All data were analyzed and categorized using the constant comparative method with independent review by three researchers.

Results: Twenty six interns caring for 82 patients were interviewed after receiving sign-out from another intern. Twenty five discrete incidents, all the result of communication failures during the preceding patient sign-out, and 21 worst events were described. Inter-rater agreement for categorization was high ( $\kappa$ 0.781.00). Omitted content (such as medications, active problems, pending tests) or failure-prone communication processes (such as lack of face-to-face discussion) emerged as major categories of failed communication. In nearly all cases these failures led to uncertainty during decisions on patient care. Uncertainty may result in inefficient or suboptimal care such as repeat or unnecessary tests. Interns desired thorough but relevant face-to-face verbal sign-outs that reviewed anticipated issues. They preferred legible, accurate, updated, written sign-out sheets that included standard patient content such as code status or active and anticipated medical problems.

Conclusion: Communication failures during sign-out often lead to uncertainty in decisions on patient care. These may result in inefficient or suboptimal care leading to patient harm.
\end{abstract}

examined the hand-off process confirm that it is variable, unstructured, and prone to error. ${ }^{12}{ }^{13}$ To improve the integrity and quality of this process, the nature and effects of communication failures that may lead to patient harm need to be understood. ${ }^{14}$ This study focuses on those communication failures that result in adverse events or near misses, defined here as "critical incidents". Using these critical incidents, this study characterizes the failures in communication that occur during the in-hospital sign-out of patient care between physicians-in-training and suggests areas for improvement.

\section{METHODS}

\section{Transfer ("sign-out") of inpatient care at the University of Chicago}

To transfer care of their patients, internal medicine first year resident physicians (interns) at the University of Chicago Hospitals prepare and print a Microsoft Word document with pertinent patient information. These documents are then verbally summarized by departing (primary) interns to covering interns who remain on duty overnight ("on-call") to provide night coverage for their own patients as well as the hospitalized patients of other interns ("cross-coverage"). Covering interns may refer to and modify these documents with handwritten notes in the margins when patient care issues arise on one of the patients that they are covering during their on-call period. When the primary interns return the next morning, they contact their respective covering intern who is now "post-call" to receive an update of events that occurred overnight and to retrieve the written sign-out document with the updated notes from covering physicians (Appendix 1). nations because of the efforts to reduce duty hours for medical trainees. ${ }^{11-13}$ The few studies to date which have 
Box 1 Intern interview questions regarding sign-out

- Question designed to elicit information about adverse events and near misses: "Was there anything bad that happened or almost happened last night because the (VERBAL/WRITTEN) sign-out wasn't as good as it could have been $?^{\prime *}$

- Question designed to elicit information about worst event experienced in past year: "Can you tell me the single most severe adverse event that you were involved in over the last year that resulted from a deficient sign-out?"

- Question designed to elicit information about ideas for improvement: "Regardless of whether anything went wrong or almost went wrong and thinking about what should be included in a sign-out, is there anything about the (VERBAL/WRITTEN) sign-out that you received that you think should have been better?"*

${ }^{*}$ Question repeated for verbal and written sign-out.

\section{Data collection}

Both primary interns and covering interns were privately interviewed by an investigator (VA) without prior notification of the purpose of the interview after one night of crosscover care on patients. The critical incident technique was used to solicit communication failures during verbal and written sign-out. Initially developed to study aviation accidents, this technique can broaden knowledge of sparingly documented or poorly understood areas using factual reports of an individual's observation of their own behavior or of others. ${ }^{15}{ }^{16}$ To identify communication failures that possibly led to patient harm, interns were asked to identify and describe near misses or adverse events that took place either as a result of a poor written or verbal sign-out from the preceding shift (box 1). They were also asked to describe the most severe adverse event they could recall in the past year due to a suboptimal sign-out and, lastly, to evaluate their peers' written and verbal sign-out and suggest areas of improvement. Covering interns were interviewed at $7 \mathrm{am}$ on their post-call day and primary interns were interviewed starting at noon on the day of receiving the sign-out from covering interns (fig 1).

To ensure all interns were experienced with cross-coverage at the time of the interviews, interviews were conducted in the last quarter of the academic year. To minimize the effect on future behavior, interviews were only performed on the last weekday of the month-long inpatient general medicine rotation. Because interns rotate on the inpatient general medicine service more than once, the last weekday of the months of March and June were chosen to provide an adequate sample of representative interns while attempting to reduce the number of interns who would be interviewed more than once.

\section{Data analysis}

All interview data were stripped of identifying information and replaced with labels to reflect intern's call status (covering or primary) and unique voice (1, 2, 3, etc). These data were then reviewed by three investigators (VA, JKJ, DL) and analyzed by the constant comparative method. ${ }^{17}$ Using this inductive approach with no a priori assumptions, incident reports were compared using a stepwise approach. ${ }^{18}$ Firstly, data from each incident were categorized during an open coding process. Secondly, incidents were compared across interviews to yield integration or refinement of categories, including grouping related categories or creation of sub-categories. By using the core or main categories that emerged, this categorical scheme was then selectively applied to all the data. Kappa statistics were used to determine interrater agreement for the categorization of critical incidents by the three independent reviewers. Reconciliation of all discrepancies was achieved by consensus.

The Institutional Review Board of the Biological Sciences Division of the University of Chicago approved this study.

\section{RESULTS}

All 30 interns who rotated on the inpatient general medicine service in March and June 2004 were eligible for participation in the study. Of these, 26 interns collectively caring for 82 patients were interviewed after two different call nights. Twenty five distinct incidents were reported, all of which were the result of a communication failure in the written or verbal sign-out from the preceding shifts. Interns also reported 21 worst events due to deficient sign-out that occurred in the preceding year. Inter-coding agreement for categorization of incidents was high with kappa statistics ranging from 0.78 to 1.0 per category.

The eight covering interns (four from each call night) cited failures of communication at sign-out from the prior evening, while remaining primary interns described failures at retrieval of sign-out that morning. In several instances, communication failures described at both times involved the same patient. For example, a covering intern (Cl) reported:

"I got over six calls yesterday for a patient who had hypertension whose blood pressure is frequently over 200. We never discussed this and when I went to the chart, I realized that this has been a problem for the last 2 days ... The patient was requiring a lot of $I V$ medication to control his blood pressure..."

Later that day the primary intern (P1), after communicating with this covering intern, reported:

"I wasn't told [by the covering intern] that there was a patient who had high blood pressure and that they needed to give IV hydralazine."

Two major categories referred to the contributing factor in the communication failure. One was referred to in the analysis as "content omissions" in which critical information needed to care for a patient was not communicated, either verbally or in writing, during the hand-off process. Incidents in this category could be further classified as: (1) failure to report an active medical problem; (2) failure to report a medication or other treatment; (3) failure to report pending or ordered diagnostic tests or consults (table 1).

Of these, the most common was a failure to report an active medical problem. In several cases this active medical problem had already been worked up but covering interns felt that they were "starting from scratch".

The other major contributor to communication failures referred to failure-prone communication processes. This was further divided into three sub-categories (table 1). In at least two events, interns cited lack of face-to-face communication as a factor in a critical incident. In two other events, primary interns reported that handwritten notes on the written signout from covering interns were unclear or illegible, leading to confusion regarding a patient care issue. Lastly, in three events interns described a failure in communication resulting from the use of a second covering resident physician referred to by the intern as "night float". The night float physician, who may care for patients between midnight and $7 \mathrm{am}$, results in an additional hand-off for each patient in a 24 hour period as follows: (1) primary intern to covering intern; (2) covering intern to night float; (3) night float to primary intern. In all of these events an initial covering intern had recorded illegible comments or made unclear verbal 


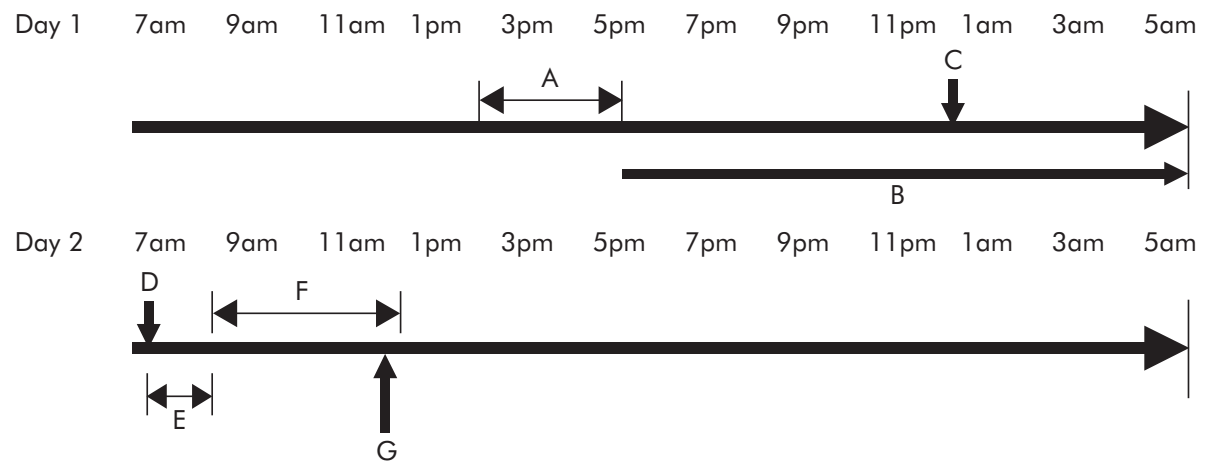

(A) 2-5pm: Primary interns finish their work and verbally summarize patients to covering interns who are on call (Verbal sign-out). Also provide covering interns with written MS Word document (written sign-out).

(B) 5pm-7am: On-call interns respond to calls and perform any necessary tasks for patients they are covering (cross-covering). May make handwritten notes on written sign-out for covering interns.

(C) 12am: Night float physicians arrive and busy on-call interns may choose to sign over their cross - coverage to night float.

Figure 1 Timeline showing interview procedure for interns.

comments to a night float physician. The following morning the primary intern received no verbal communication from the night float physician regarding these events, resulting in the primary intern having actively to seek out the initial covering intern.

Regardless of what contributed to the communication failure, in nearly all cases $(21 / 25)$ these failures led to uncertainty by the intern during patient care decisions. The frequent use of phrases such as "I did not know", "I was not aware", or "I was unsure" by interns reflects this uncertainty. In nearly half the incidents reported from the preceding shift, interns attempted to resolve this uncertainty (table 2). In most cases they did this by actively soliciting information from other sources, such as interviewing the patient, looking in the chart, or seeking out the covering intern or another resident. In a few cases they had to engage in unnecessary or repeat work such as reordering tests or procedures. In some
(D) 7am: Covering interns interview $(n=4)$

7am: On-call interns, now "post-call," retrieve sign-outs from night float physicians if they opted to use night float to assist them

(E) 7am-8am: Primary interns return and contact interns to retrieve written sign-outs from primary interns.

(F) $8 \mathrm{am}-12 \mathrm{pm}$ : Primary interns round on hospitalized patients, reviewing overnight events and assess any interval change.

(G) 12pm: Primary interns interview $(n=10-12)$

Table 1 Categories of communication failure in sign-out from preceding shift

\begin{tabular}{|c|c|c|}
\hline Category (n) & Sub-category (n) & Representative incident $(n=25)^{*}$ \\
\hline $\begin{array}{l}\text { Content omissions } \\
\text { (22) }\end{array}$ & $\begin{array}{l}\text { Active medical } \\
\text { problems (9) } \\
\text { Medications or } \\
\text { treatments (11) } \\
\text { Tests or consults (10) }\end{array}$ & $\begin{array}{l}\text { "There was a patient that had hematuria and it was not indicated } \\
\text { on the sign-out. They had ordered CBI [continuous bladder } \\
\text { irrigation] and I had no idea." (C3) } \\
\text { "There was a patient who had their heparin drip turned off and it } \\
\text { was not mentioned to me that it was turned off." (P2) } \\
\text { "There was a consult that was pending that was not listed and then } \\
\text { ID [infectious disease] and pulmonary called with } \\
\text { recommendations and there was no note that these } \\
\text { recommendations were coming or what I should do with them." } \\
\text { (C2) }\end{array}$ \\
\hline \multirow[t]{2}{*}{$\begin{array}{l}\text { Failure-prone } \\
\text { communication } \\
\text { processes (8) }\end{array}$} & $\begin{array}{l}\text { Double sign-out } \\
\text { ("night float") (3) }\end{array}$ & $\begin{array}{l}\text { "One of my patients - it just said "will need bx" - I did not know } \\
\text { where, who recommended it or unclear if I was to schedule this or if } \\
\text { it had already had been scheduled. Obviously I needed to know } \\
\text { what happened before I went to see my patient so I called the } \\
\text { primary intern who was cross covering before the float came on." } \\
\text { (P4) }\end{array}$ \\
\hline & $\begin{array}{l}\text { No face-to-face } \\
\text { communication (4) }\end{array}$ & $\begin{array}{l}\text { "He called me while he was in clinic so it was brief and over the } \\
\text { phone and I would have preferred that our sign-out was face to } \\
\text { face so I had a chance to ask questions. He had to go to clinic so he } \\
\text { just put the sign-out on the wall and then called from there." (C4) } \\
\text { "The writing from the prior intern was illegible. Later on, I found } \\
\text { them and figured out what it meant." (P3) }\end{array}$ \\
\hline
\end{tabular}

*More than one category and sub-category mapped to these 25 distinct critical incidents. 
Table 2 Response to communication failure during sign-out

\begin{tabular}{lll}
\hline Category (n) & Sub-category (n) & Representative incident \\
\hline $\begin{array}{l}\text { Attempt to resolve } \\
\text { uncertainty (9) }\end{array}$ & $\begin{array}{l}\text { Unnecessary or repeat } \\
\text { work (2) }\end{array}$ & $\begin{array}{l}\text { "A patient who had a trach got disconnected. I was not even sure } \\
\text { why this patient had a trach. We had not discussed it and it was not } \\
\text { written down. We } 4 \text { belled anesthesia because the trach was pulled } \\
\text { out but later I found out that the trach was just for supplemental } \\
\text { oxygen and not necessary." (C6) } \\
\text { "There was a patient who was having pain ... and the cross-cover } \\
\text { ordered a pain medication and it was written on the sign-out but } \\
\text { not discussed. I did not know why it was ordered and then I asked } \\
\text { the patient but I felt like I should know that the patient was having } \\
\text { back pain." (P13) }\end{array}$ \\
& $\begin{array}{l}\text { Solicit information } \\
\text { from others (8) }\end{array}$ &
\end{tabular}

direct result of omitted patient data or information but instead were characterized by failure to communicate the reasoning of the primary team to the covering intern. These events often resulted in a covering intern questioning a decision made by the primary team or not understanding why it was made.

In suggesting areas of improvement for verbal sign-out, comments were classified into four major categories (table 4).

The most frequent suggestion was to verbally communicate any anticipated problems that may occur overnight. Interns also suggested that a thorough verbal sign-out that reviewed relevant medical problems was needed for effective patient care. Lastly, interns suggested that this communication should occur face-to-face. Several of these suggestions were also noted in areas of improvement for written sign-outnamely, the need to include anticipated problems and relevant information. However, there were certain suggestions unique to the improvement of written sign-out. Interns suggested that written sign-outs should contain code status, baseline mental status, pending tests, consults, and procedures (table 5).

Interns also highlighted overall features of desirable signout sheets. Several interns commented on the need to keep content on the written sign-outs updated to reflect most recent changes in medications, medical problems, or pending tests. Two interns specifically noted that there might be irrelevant information on the written sign-out. One of these interns (P8) offered an explanation by stating:
"The written sign-out has a different role than just a capture of a patient. We use it to keep track of everything but sometimes that makes it difficult to know what is going on right now since there is so much extra information on it."

Interns often use their written sign-outs as "to do" lists to remind them of their work in progress, or what psychologists refer to as a "cognitive artifact" or a tool to aid in the recollection of various tasks related to the workflow of an intern. ${ }^{19}$ However, this use may interfere with the primary function of written sign-outs, to provide information and guidance to covering physicians during care for patients.

\section{DISCUSSION}

This study of critical incidents describes a categorical scheme with which to classify communication failures during signout of patient care between physicians-in-training and makes suggestions for improvement. This taxonomy of communication failures and potential improvements may be informative in designing educational and system based interventions to improve the quality of sign-out (table 6).

However, before such improvements can be undertaken, it is important to consider why such failures occur. One probable reason is that the inevitable daily changes in the course of a patient's hospitalization makes the task of keeping information up to date increasingly difficult, potentially resulting in omissions or out of date information. Secondly, few medical trainees receive formal instruction, supervision, or receive feedback in the "handoff" process.

Table 3 Categories of failed communication in worst events due to poor sign-out

\begin{tabular}{|c|c|c|}
\hline Category (n) & Sub-category (n) & Representative description of worst event $(n=21)^{*}$ \\
\hline \multirow[t]{4}{*}{ Content omissions (17) } & $\begin{array}{l}\text { Active medical problem } \\
\text { (7) }\end{array}$ & $\begin{array}{l}\text { "I spent a lot of hours with a bowel ischemia patient who was } \\
\text { having pain and bright red blood per rectum. He had a } \\
\text { history of clots and I had called surgery, done serial exams, } \\
\text { ordered a lactate. Later, the next morning, I found out that } \\
\text { these were all useless studies because he had been like that } \\
\text { for } 3 \text { days." (P5) }\end{array}$ \\
\hline & Code status (5) & $\begin{array}{l}\text { "There was a patient who I was cross covering who ended } \\
\text { crashing and it was not verbally conveyed or written in the } \\
\text { sign-out that the patient was not a full code. The patient was } \\
\text { coded for over a minute ... we were definitely doing chest } \\
\text { compression before someone realized that the patient was } \\
\text { not a full code." (C2) }\end{array}$ \\
\hline & Baseline status (2) & $\begin{array}{l}\text { "A patient was transferred to the ICU because it appeared } \\
\text { that they were worse from the baseline. Of course we did not } \\
\text { really know what the baseline was and it turned out that the } \\
\text { patient had bad right sided heart failure which would have } \\
\text { been helpful to know during the resuscitation as the patient } \\
\text { was coding." (C7) }\end{array}$ \\
\hline & $\begin{array}{l}\text { Rationale of primary } \\
\text { team (5) }\end{array}$ & $\begin{array}{l}\text { "They appeared to be septic and I was unclear why the } \\
\text { patient was not on antibiotics and it was not described or } \\
\text { communicated on the sign-out why not. I ended up putting the } \\
\text { patient on antibiotics but it was a difficult decision since I did } \\
\text { not know the reasoning of the primary team." (P6) }\end{array}$ \\
\hline
\end{tabular}


Table 4 Suggested improvements for verbal sign-out

\begin{tabular}{|c|c|}
\hline Category (n) & Sample comments $(n=10)$ \\
\hline Anticipate (5) & $\begin{array}{l}\text { "I would like to know who might bring me trouble or } \\
\text { who is going to get sick. I think that it is helpful to } \\
\text { prioritize sickness and what you are supposed to } \\
\text { do." (P7) }\end{array}$ \\
\hline Pertinent (2) & $\begin{array}{l}\text { "XX tends to editorialize during verbal sign-out than } \\
\text { to discuss the pertinent issues. For example, 'this } \\
\text { lady is really nice and her family is from Michigan'. } \\
\text { This does not help me; I would prefer a concise } \\
\text { review of the patients' problems." (C8) }\end{array}$ \\
\hline Face-to-face (2) & $\begin{array}{l}\text { "In general, I think that verbal sign-out is helpful but } \\
\text { some people just say pick up the sheets and want to } \\
\text { do it over the phone and this upsets me. This } \\
\text { happens all the time when I am in the middle of } \\
\text { post-call rounds, I would prefer to have time to } \\
\text { interact with them and instead they just come to pick } \\
\text { up the sheets from my resident. I try to track them } \\
\text { down and let them know if something took place on } \\
\text { one of their patients." (P2) }\end{array}$ \\
\hline Thorough (1) & $\begin{array}{l}\text { "In general, they don't tell you everything that they } \\
\text { did. There are different criteria for what is minor } \\
\text { (e.g. holding a BP med). But increasing a dose is } \\
\text { important to know." (P8) }\end{array}$ \\
\hline
\end{tabular}

Without such guidance, variability in the performance and effectiveness of this communication is almost certain. One possible approach to address these problems is standardization. In fact, the implementation of standardized "hand-off" communications is a National Patient Safety goal identified by the Joint Commission on Accreditation of Healthcare Organizations. Although little evidence or instruction exists to inform such standardized practices, the taxonomy presented in table 6 can form the foundation of systematic and educational interventions to improve sign-out. ${ }^{20}$

One approach to standardization of written sign-out is the use of sign-out templates. These sign-out templates could include required fields for high yield content, such as code status, to prevent content omissions. A more technologically oriented approach to standardization described by others is a computerized sign-out system..$^{21} 22$ A computer based system can definitely improve legibility and potentially reduce content omissions through the use of standard fields. Higher level functions such as prompts to update information or interfacing with existing patient data repositories may also be helpful improvements.

However, it is important to recognize that a technological solution cannot alone substitute for a successful "communication act". ${ }^{23}$ Effective verbal communication is still important to ensure proper transmission of information. For instance, the replacement of a telephone call for reporting critical laboratory values in an emergency room with an electronic results reporting system with no verbal communication resulted in $45 \%$ of emergency laboratory results going unchecked. ${ }^{24}$ The use of more structured verbal communication such as "read-backs" during telephone calls of critical laboratory results has been shown to decrease errors in telephone laboratory reporting. ${ }^{25}$ Lack of or ineffective verbal communication at the time of hand-offs has emerged as a common theme surrounding adverse event and near miss situations in nursing. ${ }^{26}$ These findings, in conjunction with this study, suggest that proper verbal communication during sign-out is important for safe patient care.

For this reason, standard educational programs should be considered to train residents to communicate effectively at the time of hand-offs. The richness and effectiveness of faceto-face communication in the context of hand-offs in medicine and other industries should be emphasized..$^{27}$ The need for complete but relevant sign-outs reflects the delicate balance between delivering too much or too little information, a sentiment also expressed by nurses for their verbal communication during "report" or shift change. ${ }^{29}$ Achievement of this skilful verbal communication during sign-out may require adoption of standard language. ${ }^{30}$ One possible tool to facilitate this is the Situational Debriefing Model, otherwise known as "SBAR" (situation, background, assessment, and recommendation). This model, which originated in the Navy, can be used in health care to improve communication of critical information in a timely and orderly fashion. ${ }^{31}$ The use of critical incident analysis and peer evaluations, as described in this study, is a potential way for teaching and improving resident sign-out.

Table 5 Suggested improvements for written sign-out

\begin{tabular}{|c|c|c|}
\hline Category (n) & Sub-category (n) & Sample comments $(n=20)^{*}$ \\
\hline Patient content (13) & $\begin{array}{l}\text { Code status (3) } \\
\text { Anticipated problems (4) } \\
\text { Active problems (4) } \\
\text { Baseline exam (3) } \\
\text { Pending test or consults (4) }\end{array}$ & $\begin{array}{l}\text { "The code status would be helpful." (C2) } \\
\text { "A great IF/then section which is really important to } \\
\text { troubleshoot problems." (C9) } \\
\text { "It would be helpful to have a specific section that } \\
\text { chronicles cross-cover events in prior nights." (P9) } \\
\text { "In general, neuro status if offen not included and a } \\
\text { patient has mental status changes so you don't know } \\
\text { what the baseline is." (P10) } \\
\text { "If they have tests or consults ending, it needs to be } \\
\text { pointed out." (C10) }\end{array}$ \\
\hline Overall features (8) & $\begin{array}{l}\text { Legible (3) } \\
\text { Relevant (2) } \\
\text { Accurate (5) } \\
\text { Updated (4) }\end{array}$ & $\begin{array}{l}\text { "Often times you don't understand what has been } \\
\text { written down because it is illegible or incomplete } \\
\text { and that is all that you have to go on." (P4) } \\
\text { "We take up a lot of room on history data that may } \\
\text { not be important for cross cover." (P9) } \\
\text { "Room numbers can be incorrect and then you have } \\
\text { to call bed access to find the patient." (P11) } \\
\text { "In general, room numbers and medications are not } \\
\text { updated. The worst thing is when things aren't } \\
\text { updated. Last week when I was on call, a patient } \\
\text { had written down that I should check q4 hour CBCs. } \\
\text { Initially, I did not know that it was left over. I } \\
\text { assumed when it wasn't in the computer, that the } \\
\text { CBC was not done." (P12) }\end{array}$ \\
\hline
\end{tabular}

*More than one category and sub-category mapped to these 20 distinct suggestions for improvements. 
Table 6 Taxonomy of sign-out quality

\begin{tabular}{lc}
\hline Poor sign-out & Effective sign-out \\
\hline Content omissions & Written sign-out \\
Medications or treatments & Patient content \\
Tests or consults & Code status \\
Medical problems & Anticipated problems \\
Active & Baseline examination \\
Anticipated & Pending test or consults \\
Baseline status & Overall features \\
Code status & Legible \\
Rationale of primary team & Relevant \\
& Accurate \\
& Up to date \\
Failure-prone communication & Verbal sign-out \\
processes & Anticipate \\
Lack of face-to-face & Pertinent \\
communication & Face-to-face \\
Double sign-out ("night float") & Thorough \\
Illegible or unclear handwriting & \\
& \\
\hline
\end{tabular}

This study has several limitations. Firstly, it examines the sign-out processes of a group of interns at one teaching hospital. Because of variability between institutions in mechanisms of sign-out or coverage systems, this study is limited in the extent to which it is generalizable. However, given the frequency of sign-out, these findings do enhance the limited existing literature by providing a framework and method for evaluating communication failures in this process. Secondly, these findings are subject to limitations of the critical incident interviews. It is possible that expectation-led interviewer effects, although reportedly minimal, may have influenced the data collection..$^{32}$ These effects, which occur when the interviewer may inadvertently influence respondents to produce outcomes consistent with a priori expectations, would manifest itself as an increase in the number of communication failures reported. However, given the reliability and predominance of categories that emerged, it is less likely that the distribution of types of failures would change significantly. It is also equally possible that the identity of the interviewer (in this case a former chief medical resident) may have influenced data collection. ${ }^{33}$ For example, underreporting of communication failures due to concerns for a perceived potential of disciplinary action for peers may have limited incident reporting. To minimize this effect, interns were informed that all data would be stripped from any identifying information and restricted only to investigator use during the consent process. In addition to these limitations, data on sign-out quality in this study are limited by the content of the interviews. Supplementation with methods such as direct observation or audio recording, which may impair this process initially through observer effects, would probably yield a richer data set over time. ${ }^{34}$ For instance, we lack detailed data on the place, time, length, or presence of interactive questioning of the verbal communication that took place, all of which could be obtained using formal observation. Unfortunately, the use of these alternative methods would be costly given the sporadic nature of sign-out and the time to code field notes and audiotapes. In restricting this study to critical incidents, the data and observations are subject to hindsight bias or oversimplification of factors that led to error due to retrospective analyses. ${ }^{35}$ We may overlook more complex system factors that were involved in a failed communication such as workload, time, environment, and attitude. For these reasons, this study is by no means definitive but, instead, a preliminary attempt to understand the communication failures that occur during sign-out. To understand this complex process, further
Key messages

- Communication failures during sign-out are often characterized by content omissions or failure-prone communication processes.

- These failures often lead to uncertainty in decisions about patient care which may result in inefficient or suboptimal care.

- A taxonomy of effective and poor sign-out is presented which may be informative in designing educational and system-based interventions to improve the quality of sign-out.

research should be undertaken with an emphasis on studying system factors and human performance in a broader context rather than through failures alone. ${ }^{36}$ Lastly, the results from this qualitative study cannot be statistically projected across a population. However, the methods and framework presented can be used to inform future quantitative studies that can assess rates and types of failures, or quantitatively evaluate the effect of an intervention such as computerized sign-out or a verbal sign-out educational program.

\section{ACKNOWLEDGEMENTS}

The authors thank Vivian Chang, Carrie Dunphy, and Jennifer Higa for their excellent research assistance.

\section{Authors' affiliations}

V Arora, J Johnson, D Lovinger, D O Meltzer, Department of Medicine, University of Chicago, Chicago, IL, USA

J Johnson, American Board of Medical Specialties, Evanston, IL, USA H J Humphrey, Pritzker School of Medicine, University of Chicago, Chicago, IL, USA

D O Meltzer, Department of Economics and Harris School of Public Policy, University of Chicago, Chicago, IL, USA

This research was supported by the Department of Medicine at the University of Chicago.

None of the authors has any competing interests.

\section{APPENDIX 1: STRUCTURE OF INPATIENT GENERAL MEDICINE SERVICE AT UNIVERSITY OF CHICAGO}

The general medicine inpatient service consists of eight teams of one attending, one resident (second or third year house staff), and two interns (first year house staff). Teams are designated by a letter $(\mathrm{A}, \mathrm{B}, \mathrm{C}$, or $\mathrm{D})$ and number ( 1 or 2 ). Teams designated with the same letter perform their required extended duty hour shifts ("call") on the same day, every fourth day. These extended shifts are from 8 am to 8 am the following day, at which time the intern is "post-call". During the on-call period, interns designated with the same number are responsible for caring for patients on the other three teams in their assigned numerical group after those teams leave the hospital. For example, intern $\mathrm{Al}$ takes call on Monday with intern A2, but is responsible for all of the patient care (also known as "cross-coverage") for interns Bl, $\mathrm{Cl}$, and Dl after those interns leave the hospital.

The official transfer of care between the primary intern to the covering intern, who is on-duty or "on-call", takes place through both a handoff process known as "sign-out". This sign-out can refer to the verbal communication at the time of the handoff and/or to the written Microsoft Word document that contains a synopsis of the primary intern's patients. The next morning, primary interns return from home and contact the covering intern, who is now "post-call", to retrieve their 
written sign-out and receive a verbal update of any critical issues.

\section{REFERENCES}

1 Wilson RM, Runciman WB, Gibberd RW, et al. The quality in Australian health care study. Med J Aust 1995;63:458-71.

2 Lingard L, Espin S, Whyte S, et al. Communication failures in the operating room: an observational classification of recurrent types and effects. Qual Saf Health Care 2004;13:330-4.

3 Sutcliffe KM, Lewton E, Rosenthal MM. Communication failures: an insidious contributor to medical mishaps. Acad Med 2004;79:186-94.

4 Department of Health. Organisation with a memory, Report of an Expert Group on Learning from Adverse Events in the NHS. London: HMSO, 2000.

5 Joint Commission on Accreditation of Healthcare Organizations. Sentinel event statistics. Available at: http://www.jcaho.org/ accredited+organizations/sentinel+event/sentinel+event+statistics.htm (accessed 1 May 2005).

6 Lally S. An investigation into the functions of nurses' communication at the inter-shift handover. J Nurs Manag 1999;7:29-36.

7 Sherlock C. The patient handover: a study of form, function and efficiency. Nursing Standard 1995;52:33-6.

8 Beach C, Croskerry P, Shapiro M. Center for Safety in Emergency Care. Profiles in patient safety: emergency care transitions, Acad Emerg Med 2003; 10:364-7

9 Thakore S, Morrison W. A survey of perceived quality of patient handover by ambulance staff in the resuscitation room. Emerg Med J 2001;18:293-6.

10 Peterson LA, Brennan TA, O'Neil AC, et al. Does housestaff discontinuity of care increase the risk for preventable adverse events? Ann Intern Med 1994;121:866-72.

11 Mukherjee S. Becoming a physician: a precarious exchange. N Engl J Med 2004;351:1822-4.

12 Roughton VJ, Severs MP. The junior doctor handover: current practices and future expectations. J R Coll Physicians Lond 1996;3:213-4.

13 Bomba DT, Prakash R. A description of handover processes in an Australian public hospital. Aust Health Rev 2005;29:68-79.

14 Cook RI, Render M, Woods DD. Gaps in the continuity of care and progress on patient safety. BMJ 2000;320:791-4

15 Flanagan JC. The critical incident technique. Psychol Bull 1954;51:4, 327-59.

16 Gremler DD. The critical incident technique in service research. J Serv Res 2004; 7:65-89.

17 Boeije H. A Purposeful approach to the constant comparative method in the analysis of qualitative interviews. Quality and Quantity 2002;36:391-40.

18 Glaser BG, Strauss A. Discovery of grounded theory. Strategies for qualitative research. Sociology Press (http://www.groundedtheory.com/index1.html), 1967.

19 Volpp KG, Grande D. Residents' suggestions for reducing errors in teaching hospitals. N Engl J Med 2003;348:851-5.
20 Joint Commission on Accreditation of Healthcare Organizations. Joint Commission announces 2006 national patient safety goals for ambulatory care and office-based surgery organizations. 2005. Available at http:// www.jcaho.org/news+room/news+release+archives/ 06_npsg_amb_obs.htm (accessed 1 September 2005).

21 Petersen LA, Orav EJ, Teich JM, et al. Using a computerized sign-out program to improve continuity of inpatient care and prevent adverse events. Jt Comm J Qual Improv 1998;24:77-87.

22 Van Eaton EG, Horvath KD, Lober WB, et al. A randomized, controlled trial evaluating the impact of a computerized rounding and sign-out system on continuity of care and resident work hours. J Am Coll Surg 2005;200:538-45.

23 Ash JS, Berg M, Coiera E. Some unintended consequences of information technology in health care: the nature of patient care information systemrelated errors. J Am Med Inform Assoc 2004;11:121-4.

24 Kilpatrick ES, Holding S. Use of computer terminals on wards to access emergency test results: a retrospective audit. BMJ 2001;322:1101-3.

25 Barenfanger J, Sautter RL, Lang DL, et al. Improving patient safety by repeating (read-back) telephone reports of critical information. Am J Clin Pathol 2004;121:801-3.

26 Ebright PR, Urden L, Patterson E, et al. Themes surrounding novice nurse nearmiss and adverse-event situations. J Nurs Admin 2004;34:531-8.

27 Patterson ES, Roth EM, Woods DD, et al. Handoff strategies in settings with high consequences for failure: lessons for health care operations. Int $J$ Qual Health Care 2004; 16:125-32.

28 Cockburn A. Agile Software Development. Boston: Addison-Wesley, 2002

29 Kerr MP. A qualitative study of shift handover practice and function from a socio-technical perspective. J Adv Nurs 2002;37:125-34.

30 Leonard M, Graham S, Bonacum D. The human factor: the critical importance of effective teamwork and communication in providing safe care. Qual Saf Health Care 2004;13(Suppl I):i85-90.

31 British Medical Association. Safe handover: safe patients. Guidance on clinical handover for clinicians and managers. London: BMA, Available at http://www.bma.org.uk/ap.nsf/Content/Handover/\$file/Handover.pdf (accessed 22 December 2004).

32 Clarke P, Sproston K, Thomas R. An investigation into expectation-led interviewer effects in health surveys. Soc Sci Med 2003;56:2221-8.

33 Chew-Graham CA, May CR, Perry MS. Qualitative research and the problem of judgement: lessons from interviewing fellow professionals. Fam Pract 2002; 19:285-9.

34 Holden JD. Hawthorne effects and research into professional practice. J Eval Clin Pract 2001;7:65-70.

35 Henriksen $\mathrm{K}$, Kaplan $\mathrm{H}$. Hindsight bias, outcome knowledge and adaptive learning. Qual Saf Health Care 2003;12(Suppl II):ii46-50.

36 Cook RI, Woods DD, Miller C. A tale of two stories: contrasting views on patient safety. Chicago, IL: National Patient Safety Foundation, 1998, Available at www.npsf.org/exec/report.html (accessed 1 May 2005).

\section{bmjupdates+}

bmiupdates+ is a unique and free alerting service, designed to keep you up to date with the medical literature that is truly important to your practice.

bmjupdates+ will alert you to important new research and will provide you with the best new evidence concerning important advances in health care, tailored to your medical interests and time demands.

Where does the information come from?

bmiupdates+ applies an expert critical appraisal filter to over 100 top medical journals A panel of over 2000 physicians find the few 'must read' studies for each area of clinical interest

Sign up to receive your tailored email alerts, searching access and more...

www.bmjupdates.com 